\title{
Uso de metodologia participativa na elaboração de Plano Municipal de Gestão de Resíduos da Construção Civil
}

\section{Use of participatory methodology in the development of Municipal Construction and Demolition Waste Management Plan}

Data de entrada: 23/05/2017

Data de aprovação: 07/07/2017

\section{Resumo}

As Resoluções Conama n 307/02 e n 448/12, em conjunto com a Política Nacional de Resíduos Sólidos, estabelecem a obrigatoriedade da elaboração dos Planos Municipais de Gestão de Resíduos da Construção Civil (PMGRCC), os quais são imprescindíveis para a obtenção de recursos junto à União. Nesse contexto, este trabalho teve como objetivo apresentar a metodologia participativa na elaboração de PMGRCC, a partir do estudo de caso do município de Limeira (SP), e discutir os aspectos relevantes da participação de diferentes atores da sociedade no planejamento da gestão municipal dos resíduos da construção civil (RCC). A análise das etapas da elaboração do plano mostrou que a união de esforços e conhecimentos de diferentes setores da sociedade envolvidos com o gerenciamento dos RCC resultou na construção de um plano com um diagnóstico detalhado do município, incluindo as suas peculiaridades, o que possibilitou o estabelecimento das metas, programas e ações condizentes com a realidade local. Palavras-chave: Resíduos da construção civil. Plano municipal. Metodologia participativa.

\section{Abstract}

The Resolutions Conama no 307/02 and no 448/12, in conjunction with the National Solid Waste Policy, establish the obligation to prepare the Municipal Management Plans for Construction and Demolition Waste (MMPC$D W)$, which are mandatory for obtaining resources from the Federal Government. In this context, this work aims to show the participatory methodology for MMPCDW elaboration, from the case study of the municipality of Limeira (SP), and discuss the relevant aspects on different society agent in the management plan for construction and demolition waste (CDW). The analysis of the plan steps elaboration showed that the union of efforts and knowledge resulted in the elaboration of a plan with a detailed diagnosis of the municipality, including its peculiarities, which made possible the establishment of the goals, programs and actions in keeping with the local reality. Keywords: Construction and demolition waste. Municipal plan. Participatory methodology. 


\section{INTRODUÇÃO}

Os resíduos da construção civil (RCC), conhecidos popularmente como entulhos, são aqueles provenientes de construções, reformas, ampliações, demolições, entre outras atividades do setor da construção civil. Segundo Osmani (2011), as principais causas de sua geração podem estar relacionadas a falhas no projeto, gestão e planejamento da obra; uso de técnicas construtivas "artesanais" e mão de obra não qualificada, além de problemas com o recebimento, armazenamento, transporte e manipulação dos materiais.

Em 2015, os municípios brasileiros coletaram aproximadamente 45 milhões de toneladas de RCC, o que corresponde a geração per capita de 0,605 kg.habitante- ${ }^{-1} \cdot$ dia $^{-1}$ (ABRELPE, 2016). Considerando-se que esses valores não incluem os resíduos coletados por empresas privadas, as quantidades geradas são ainda maiores, o que exige atenção quanto ao seu manejo.

Com a promulgação do Estatuto das Cidades em 2001, surge a exigência da adoção de políticas setoriais articuladas e sintonizadas com o Plano Diretor do Município, sendo a gestão dos resíduos sólidos uma dessas políticas (PINTO; GONZÁLEZ, 2005). Nesse sentido, em 2002, o Conselho Nacional de Meio Ambiente (Conama), considerando a necessidade da criação de diretrizes para a efetiva redução dos impactos ambientais gerados pelos resíduos da construção civil, publica a Resolução $n^{\circ} 307$, contendo as principais diretrizes para o correto gerenciamento destes resíduos nos municípios brasileiros.

A Resolução Conama n 307/02 passou por atualizações, uma delas foi a Resolução n 448/12, a qual traz novas definições e altera alguns critérios relacionados ao gerenciamento dos RCC em território nacional. Em termos gerais, o Conama adaptou a Resolução n 307 à Política Nacional de Resíduos Sólidos (PNRS); confirmou a responsabilidade dos grandes geradores na elaboração e implantação dos Planos de Gerenciamento de RCC (PGRCC); e instituiu o prazo de junho de 2013 para elaboração e implantação dos Planos Municipais de Gestão de RCC (PMGRCC) pelos municípios (BRASIL, 2002; BRASIL, 2012a).

Segundo a PNRS, a responsabilidade compartilhada deve ser vista como diretriz fundamental para a gestão dos resíduos sólidos, em que todos os setores da sociedade terão cada qual uma parte da responsabilidade pelos resíduos sólidos gerados (BRASIL, 2010). Nesse contexto, no processo de elaboração dos Planos de Gestão de Resíduos Sólidos, o diálogo possui papel estratégico e torna-se mais eficiente quando incentiva a participação de grupos organizados e entidades representativas dos setores econômicos e sociais do Estado e de cada comunidade. Para isso, o Poder Público deve assumir papel orientador e provocador do diálogo com a sociedade; sendo assim, os conselhos municipais são um dos principais mecanismos para garantir a participação da sociedade nas discussões sobre políticas públicas (BRASIL, 2011; 2012b).

A participação requer consciência sobre os atos, desse modo, os envolvidos devem possuir compreensão sobre o processo que estão vivenciando (TENÓRIO e ROZENBERG, 1997). Por isso, além do incentivo da criação de conselhos municipais, a divulgação dos dados sobre os resíduos é essencial, constituindo um fator de mobilização e controle da sociedade sobre os serviços públicos (BRASIL, 2011; 2012b). De acordo como Gomes et al. (2014), a elaboração de um plano de gestão participativa possibilita a construção de políticas de duração mais longa, garantindo o alcance social. No entanto, menos de $35 \%$ dos municípios brasileiros possuem Conselhos de Meio Ambiente.

A gestão municipal dos RCC envolve diversos atores com percepções e interesses diferentes em relação aos RCC. Pequenos e grandes geradores desejam destinar os resíduos gerados a um custo 
acessível, a população exige da prefeitura uma cidade limpa, os órgãos de limpeza pública almejam atender a legislação ambiental sem extrapolar o uso dos recursos disponíveis e, por outro lado, os transportadores precisam lucrar com a atividade de coleta e destinação dos RCC (FERNANDES e SILVA FILHO, 2017). Desse modo, conforme destacam Carbone et al. (2015), a participação da sociedade no processo de tomada de decisão é um elemento importante na gestão ambiental municipal, e os instrumentos participativos são essenciais para dar transparência à política urbana, cuja ausência pode ser considerada uma das causas da má gestão pública.

Nesse sentido, este artigo tem por objetivo apresentar a metodologia participativa na elaboração de planos municipais de gestão de resíduos da construção civil, a partir do estudo de caso do município de Limeira (SP), e discutir os aspectos relevantes da participação de diferentes atores da sociedade no planejamento da gestão municipal de resíduos da construção civil. Desde 2011, o Município possui a Lei $n^{\circ}$ 4.812/11 (LIMEIRA, 2011), que regulamenta as etapas do manejo dos RCC, desde a coleta até a destinação final. O Município dispõe de um aterro para recebimento de resíduos da construção civil e resíduos inertes, e Ecopontos para o recebimento de pequenos volumes de RCC, distribuídos em cinco regiões principais do Município. Apesar desses mecanismos, até então não havia um PMGRCC.

Em 2013, em atendimento à Lei Federal $n^{\circ}$ 11.445/07 (BRASIL, 2007), foi elaborado o Plano Municipal de Saneamento de Limeira, contendo um volume sobre Limpeza Urbana e Manejo de Resíduos Sólidos, o qual inclui os RCC. Entretanto, esse plano não substitui o PMGRCC. Dessa forma, em 2014 as Secretarias Municipais de Desenvolvimento Rural e Meio Ambiente, Obras e Urbanismo e de Serviços Públicos, com a colaboração de empresas contratadas para prestação de serviços no Município, elaboraram uma minuta do Plano. No decorrer do primeiro semestre de 2015, agentes de instituições públicas e privadas, relacionados com o tema, foram convidados a integrar uma ação participativa para revisão da minuta elaborada, a partir de reuniões semanais.

Apesar de existir uma quantidade considerável de trabalhos discutindo aspectos relacionados à gestão e ao gerenciamento de resíduos da construção civil (GALARZA et al., 2015; SCREMIN et al., 2014; LIMA e CABRAL, 2013; CARMO et al., 2012; ÂNGULO et al., 2011; COSTA et al., 2007; AZEVEDO et al., 2006), até o momento, foram publicados apenas estudos sobre o uso do método participativo no gerenciamento integrado de resíduos sólidos (SANTOS, 2015) e de resíduos sólidos urbanos (ORSI, 2006; LOPES, 2006; TAKENAKA, 2008), não sendo encontrada nenhuma referência na literatura que relate experiências de elaboração participativa de planos municipais de gestão de RCC no Brasil. Dessa forma, este trabalho pode contribuir na disseminação da informação sobre esse importante instrumento na gestão de resíduos da construção civil.

\subsection{0 município de Limeira e a Gestão dos RCC}

O município de Limeira está localizado a $154 \mathrm{~km}$ a noroeste da cidade de São Paulo, pertence à Região Administrativa de Campinas e às Bacias Hidrográficas dos Rios Piracicaba, Capivari e Jundiaí. Estima-se que em 2015 o Município possuía 296.440 habitantes (IBGE, 2016), sendo considerado um município de médio porte.

Desde 1981, o município de Limeira possui um aterro sanitário localizado a $10 \mathrm{~km}$ do centro da cidade (ROSADO, 2015). Atualmente, esse aterro, que opera em sistema de codisposição de resíduos domiciliares e industriais não perigosos, está em boas condições, visto que o valor do último Índice de Qualidade de Aterro de Resíduos (IQQR) foi calculado em 8,7; o valor máximo para este índice é 
10,0 (CETESB, 2015). Nesse mesmo local, chamado de Complexo Sanitário Municipal de Limeira, em células específicas para tal, são dispostos os resíduos da construção civil classe $A$ e os resíduos volumosos. A primeira célula para disposição de RCC teve operação iniciada em 2001, e atualmente está em operação a Célula III, licenciada em 2013 (Figuras 1 e 2).

Figura 1 - Construção do aterro de RCC classe A e resíduos inertes em 2013.

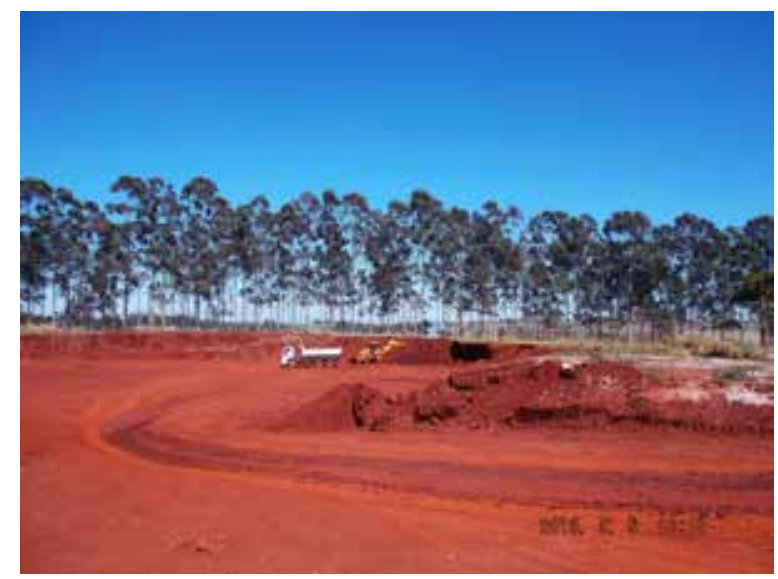

Fonte: Autor, 2016.

Figura 2 - Aterro de RCC classe A e resíduos inertes em operação desde 2014.

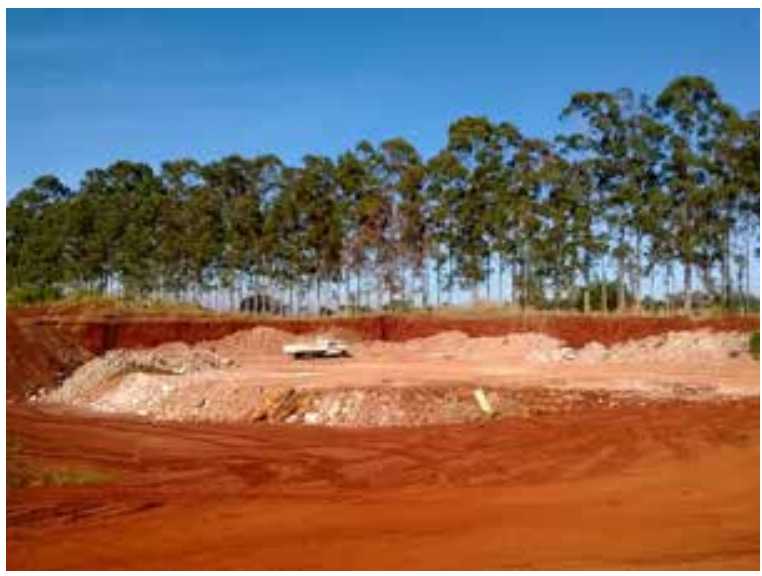

Fonte: Autor, 2016.

De acordo com o Jornal Oficial do Município, a partir de outubro de 2015 , o preço público para disposição de RCC no aterro é de $R \$ 12,00 / \mathrm{m}^{3}$, e volumes com até $1 \mathrm{~m}^{3}$ são isentos do pagamento. Atualmente existe um valor diferenciado de $\mathrm{R} \$ 89,87 / \mathrm{m}^{3}$ para caçambas contendo RCC misturados com outros tipos de resíduos, como os orgânicos, já que esses resíduos devem ser dispostos no aterro sanitário, devido ao risco de contaminação.

O sistema de gerenciamento de RCC em Limeira também contempla 11 pontos de entrega voluntária de pequenos volumes de RCC, denominados Ecopontos, localizados em cinco regiões do $\mathrm{Mu}$ nicípio (ROSADO, 2015). Esses pontos podem ser utilizados por qualquer pessoa, com o limite diário de $1 \mathrm{~m}^{3}$ por habitante, e neles somente poderão ser entregues materiais recicláveis, entulhos provenientes de construção civil e material vegetal (DALFRÉ et al., 2014).

Em 2014, foram geradas 173.750 toneladas de RCC. Esse valor corresponde aos resíduos coletados por 14 empresas transportadoras de RCC, às quantidades entregues pelos munícipes e transportadores autônomos diretamente no aterro e nos Ecopontos, à fração gerada nas obras da própria Prefeitura Municipal, e às quantidades coletadas pela empresa terceirizada que realiza a limpeza urbana e remove entulho das áreas de descarte irregular. Os grandes geradores são responsáveis pela destinação adequada de seus resíduos, por meio de contrato com empresas particulares que efetuam a coleta e a destinação final, e até o momento não há registro das quantidades geradas pelos mesmos (ROSADO, 2015).

A partir do panorama apresentado, verifica-se que em linhas gerais o Município possui um sistema de gerenciamento em consonância com as Resoluções Conama n 307/2002 e n 448/2012. Entretanto, algumas lacunas ainda precisam ser cumpridas, tais como: (a) exigir os PGRCC dos grandes geradores, a fim controlar o manejo de todo o RCC gerado no Município; (b) aprimorar o gerenciamento dos Ecopontos existentes e am- 
pliar a abrangência da reciclagem dos RCC; e, (c) intensificar os trabalhos de fiscalização e as atividades de educação ambiental, visto que os descartes irregulares ainda são frequentes em alguns pontos do município.

\section{OBJETIVOS}

Apresentar a metodologia participativa utilizada na elaboração de planos municipais de gestão de resíduos da construção civil, a partir do estudo de caso do município de Limeira-SP, e discutir os aspectos relevantes da participação de diferentes atores da sociedade no planejamento da gestão municipal de resíduos da construção civil.

\section{METODOLOGIA}

A técnica de coleta de dados utilizada foi a observação qualitativa, também chamada de observação de campo, direta ou participante (MARCONI e LAKATOS, 2011). Essa técnica foi utilizada com o objetivo de explorar e descrever as circunstâncias na qual o PMGRCC foi elaborado, compreender as etapas da construção do documento e as relações entre os atores envolvidos, identificar os principais problemas e, por fim, relacionar os fatos com a literatura a fim de auxiliar a elaboração de futuros PMGRCC. As anotações realizadas durante a coleta de dados foram anotações da observação direta, incluindo a descrição dos fatos e, anotações interpretativas, compostas por comentários pessoais sobre o tema.

A pesquisa qualitativa descritiva pode assumir diversas formas, sendo uma delas o estudo de caso (CERVO; BERVIAN; DA SILVA, 2007). Nesse sentido, esta pesquisa se caracteriza como um estudo de caso, pois refere-se ao levantamento com mais profundidade do município de Limeira. Entretanto, os dados levantados não são limitados, pois não se restringem ao caso que estuda, podendo ser generalizado para municípios com características semelhantes às de Limeira, como número de habitantes e geração per capita de RCC. A observação foi utilizada como técnica de coleta de dados, de modo assistemático e participante. A observação assistemática consistiu na coleta e registro dos fatos sem o uso de meios técnicos ou elaboração de perguntas diretas. E a observação participante ocorreu por meio da participação da primeira autora deste artigo nas reuniões de elaboração do PMGRCC de Limeira, com o objetivo de obter dados diretamente do contexto analisado, no entanto, sem o uso de instrumentos como questionários e formulários.

A elaboração do PMGRCC teve início em março de 2015, quando foram realizadas reuniões para consolidação do grupo de trabalho responsável pela revisão da minuta do PMGRCC de Limeira, e difusão das informações para os setores envolvidos na execução do plano e para a sociedade como um todo.

Os encontros foram realizados no auditório do Centro das Indústrias de São Paulo (Ciesp), unidade de Limeira, sempre com a participação dos representantes das Secretarias de Serviços Públicos, Desenvolvimento Rural e Meio Ambiente e, Obras e Urbanismo, em conjunto com as organizações que aceitaram o convite de participação (Tabela 1). Em algumas reuniões, houve a presença de representantes das empresas de locação de caçamba, responsáveis pela coleta e transporte dos RCC, das empresas prestadoras de serviço de terraplenagem, e construtoras de médio e grande porte da região, os quais compareceram para colaborar com as discussões. 
Tabela 1 - Instituições envolvidas na elaboração do PMGRCC de Limeira-SP.

\begin{tabular}{|c|c|c|}
\hline Instituição & Abrangência & Objetivos \\
\hline $\begin{array}{c}\text { Abrecon } \\
\text { (Associação Brasileira para Reciclagem dos Resíduos da } \\
\text { Construção e Demolição) }\end{array}$ & Nacional & $\begin{array}{c}\text { Instruir sobre a viabilidade técnica e econômica das Usinas de } \\
\text { Reciclagem e informar sobre o uso dos agregados reciclados no } \\
\text { Município. }\end{array}$ \\
\hline $\begin{array}{c}\text { Cetesb } \\
\text { (Companhia Ambiental do Estado de São Paulo) }\end{array}$ & Agência de Limeira & $\begin{array}{l}\text { Apresentar leis, normas e resoluções em vigor, relacionadas com } \\
\text { os RCC e experiências com a fiscalização de áreas de disposição } \\
\text { irregular de RCC. }\end{array}$ \\
\hline $\begin{array}{c}\text { Ciesp } \\
\text { (Centro das Indústrias do Estado de São Paulo) }\end{array}$ & Unidade de Limeira & Promover o envolvimento do setor industrial no PMGRCC. \\
\hline $\begin{array}{c}\text { CREA } \\
\text { (Conselho Regional de Engenharia e Agronomia) }\end{array}$ & Unidade de Limeira & $\begin{array}{c}\text { Divulgar informações sobre a gestão e gerenciamento dos RCC para } \\
\text { os profissionais da área da construção civil. }\end{array}$ \\
\hline Faculdade de Tecnologia Unicamp & Campus de Limeira & $\begin{array}{c}\text { Contribuir com experiência em pesquisas na área de gestão e } \\
\text { gerenciamento de RCC e uso de agregados reciclados e outros } \\
\text { materiais alternativos na construção civil. }\end{array}$ \\
\hline $\begin{array}{c}\text { Sincaf } \\
\text { (Sindicato Patronal das Indústrias da Construção de Limeira) }\end{array}$ & Limeira & $\begin{array}{l}\text { Contribuir com as experiências práticas do setor da construção civil } \\
\text { no município e transmitir as informações sobre o PMGRCC para seus } \\
\text { associados. }\end{array}$ \\
\hline ONG Sociedade Vida Plena & Limeira & $\begin{array}{l}\text { Compartilhar conhecimentos e experiências sobre questões } \\
\text { ambientais e projetos sociais realizados no Município. }\end{array}$ \\
\hline Usinas de Reciclagem & Limeira e região & $\begin{array}{l}\text { Apresentar os dados sobre a reciclagem de RCC no Município, } \\
\text { incluindo as dificuldades atuais do setor. }\end{array}$ \\
\hline
\end{tabular}

A Figura 3 sintetiza todas as etapas e atividades que foram desenvolvidas desde a consolidação do grupo de trabalho até a publicação do PMGRCC de Limeira no Diário Oficial do Município, em outubro de 2015. A seção "Resultados e Discussão" contempla a descrição e interpretação dos dados coletados no decorrer das etapas e atividades.

Figura 3 - Linha do tempo da elaboração do PMGRCC do município de Limeira-SP.

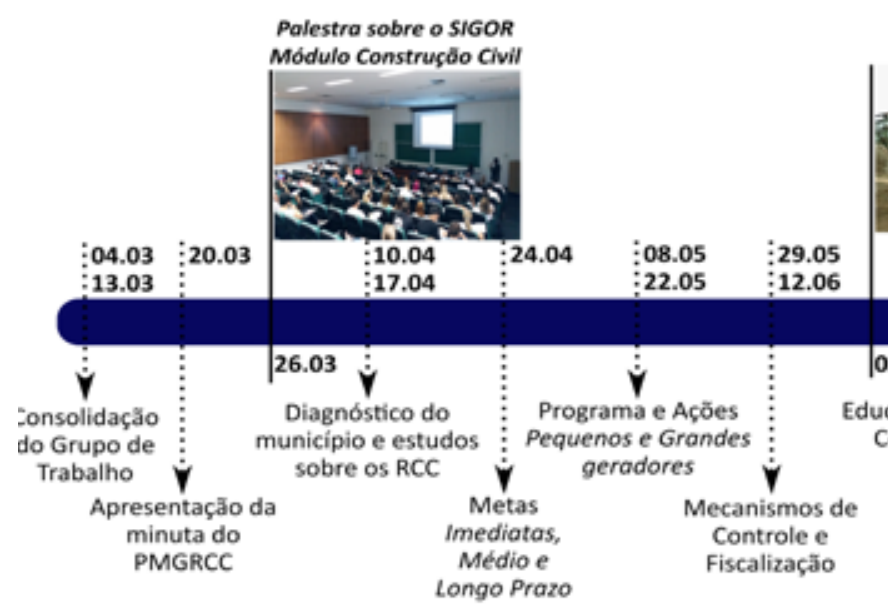

\section{RESULTADOS E DISCUSSÃO}

A elaboração do PMGRCC foi divida em três etapas, que serão apresentadas e discutidas a seguir. Ao final, é feita uma avaliação dos avanços obtidos mediante o cumprimento de algumas metas imediatas, e as perspectivas futuras para a garantia da sustentabilidade do Plano.
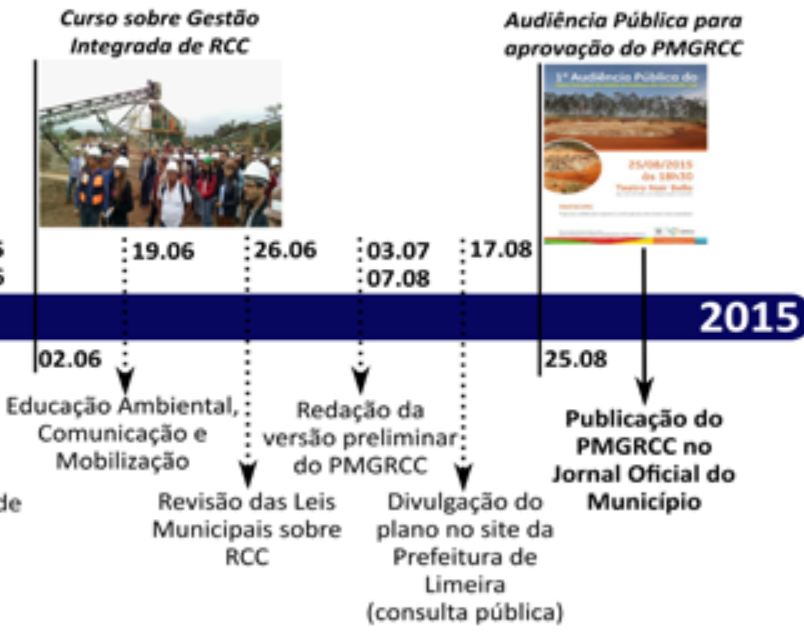

4.1 Etapas da elaboração do Plano Municipal de Gestão dos Resíduos da Construção Civil de Limeira

A primeira etapa consistiu na apresentação da minuta do Plano para os integrantes do grupo, com ênfase no diagnóstico do sistema de gerenciamento de RCC existente no município, incluindo 
os dados de geração, coleta, transporte, reciclagem e disposição final, características dos Ecopontos e das empresas terceirizadas responsáveis pelo manejo dos resíduos. Essa etapa inicial é imprescindível para a conscientização das partes envolvidas sobre a problemática dos RCC e os desafios a cerca de seu gerenciamento. Além disso, o diagnóstico é parte fundamental da elaboração do planejamento sobre a gestão e gerenciamento de resíduos sólidos.

Em relação às taxas de geração, pode-se dizer que o munícipio de Limeira possui o controle sobre as quantidades de RCC entregues nos Ecopontos, no aterro de RCC classe A e de resíduos inertes e das frações coletadas na limpeza das áreas utilizadas para a disposição irregular desse tipo de resíduo. Entretanto, assim como em outras cidades, há a dificuldade em contabilizar o volume total produzido por parte dos grandes geradores. De acordo com os dados disponibilizados pela Prefeitura de Limeira, a geração per capita em 2014, foi de 610 kg.habitante ${ }^{-1}$. ano $^{-1}$; valor superior à taxa adotada pelo Plano de Resíduos Sólidos do Estado de São Paulo, cujo valor é de $510 \mathrm{~kg} \cdot$ habitante ${ }^{-1} \cdot$ ano $^{-1}$ (SÃO PAULO, 2014).

Outro aspecto relevante que deve ser considerado na elaboração do Plano é a caracterização dos RCC. Essa informação é de fundamental importância para que sejam traçadas estratégias de gestão e gerenciamento (CÓRDOBA, 2010). A partir do conhecimento da composição física dos RCC é possível traçar estratégias para a redução, reutilização e reciclagem (CASTRO et al., 1997). Apesar de existir dados na literatura sobre a composição dos RCC, calculadas em diferentes municípios do Brasil, a composição dos RCC pode variar de forma significativa de um município para outro, visto que há influência das características locais como, por exemplo, fatores históricos, condições topográficas, desenvolvimento econômico e panorama político (SANTOS, 2007). A ausência de um estudo detalhado a respeito da caracterização dos RCC entregues nos Ecopontos e no aterro de RCC classe A é um ponto crítico na elaboração do PMGRCC de Limeira, pois a partir dessas informações seria possível a elaboração de estratégias específicas para o gerenciamento dos materiais encontrados em maior quantidade.

Antes de iniciar a segunda etapa, o grupo de trabalho, com apoio da Cetesb, promoveu uma palestra sobre o Sistema Estadual de Gerenciamento Online de Resíduos Sólidos (SIGOR) - Módulo Construção Civil. Esse sistema tem o objetivo de monitorar parte do fluxo dos RCC desde sua geração até a destinação final, incluindo transporte e destinações intermediárias (CETESB, 2015). $O$ evento foi realizado na Faculdade de Tecnologia da Unicamp e contou com a participação dos profissionais e empresários do setor da construção civil do Município, e dos alunos e professores da Faculdade. $\mathrm{O}$ uso desse sistema poderá favorecer a obtenção de dados sobre a geração dos RCC por parte dos grandes geradores, visto que todas as obras regularizadas deverão ser cadastradas. Entretanto, para que este sistema opere adequadamente, faz-se necessário um esforço da Prefeitura Municipal em disponibilizar e capacitar profissionais que terão como atividade principal a alimentação dos dados no sistema e fiscalização das informações declaradas pelas partes envolvidas (gerador, transportador e local de tratamento e/ou destinação final).

Na segunda etapa, houve a discussão dos cenários de evolução do Plano, a partir da definição das metas imediatas para 2018, médio prazo para 2022 e longo prazo para 2030. Foram definidas as seguintes metas imediatas:

- Criar um banco de dados com informações sobre a funcionalidade das pessoas físicas e jurídicas que atuam na geração, coleta, transporte, reutilização, reciclagem e disposição final dos RCC;

- Adequar os Ecopontos às normas técnicas vigentes; 
- Manter o site da Prefeitura de Limeira e demais meios de comunicação atualizados em relação às estruturas/programas/projetos existentes relacionados ao gerenciamento dos RCC;

- Solicitar a apresentação dos Controles de Transporte de Resíduos (CTRs) como requisito obrigatório na obtenção da Habite-se ou Auto de Conclusão e Certidão de Demolição para obras e demolições no território municipal;

- Solicitar e implantar o Sistema Estadual de Gerenciamento Online de Resíduos Sólidos (SIGOR) Módulo Construção Civil por meio de contato com a Secretaria de Meio Ambiente do Estado de São Paulo ou implantar um mecanismo equivalente;

- Adotar uma porcentagem para utilização do agregado reciclado de resíduos da construção civil em Obras e Pavimentações no Município, e inserir como obrigatoriedade essa porcentagem nos Termos de Referência, Memoriais Descritivos, Especificações Técnicas, Editais e outros documentos que subsidiem a contratação de Obras Públicas.

As metas de médio e longo prazo compreendem a revisão do Plano, continuidade e ampliação do sistema de fiscalização e do programa de educação ambiental, e o estudo da implantação de novos Ecopontos. $O$ encerramento do recebimento dos RCC passíveis de reciclagem no aterro de inertes integram as metas de longo prazo.

As metas estabelecidas se enquadram às metas propostas pelo Plano de Resíduos Sólidos do Estado de São Paulo (SÃO PAULO, 2014). No entanto, alguns aspectos não foram citados no PMGRCC de Limeira, como a eliminação das áreas de disposição irregular e o fomento a iniciativas de boas práticas para redução da geração de resíduos e rejeitos da construção civil. Em relação ao incentivo ao aumento da eficiência no uso dos recursos naturais, a meta sobre a adoção de uma porcentagem para utilização de agregados reciclados em obras públicas é uma das estratégias. Devido à inexistência de uma usina de reciclagem de RCC instalada no Município até o momento, as taxas de reutilização e reciclagem propostas no Plano de Resíduos Sólidos do Estado de São Paulo (70\% em 2019; 85\% em 2023 e 100\% em 2025) dificilmente serão cumpridas. Entretanto, é importante ressaltar que essas metas também não são condizentes com a maioria dos municípios brasileiros e deveriam ser revistas.

A terceira etapa teve como objetivo a definição dos programas e ações em cinco eixos, a saber: Pequenos Geradores de RCC; Grandes Geradores de RCC; Gerenciamento de RCC em Obras Públicas; Mecanismos de Controle e Fiscalização; Educação Ambiental e Mobilização Social. Os tópicos a seguir retratam os pontos mais relevantes de cada eixo.

\subsubsection{Pequenos geradores de RCC}

Segundo as Resoluções Conama no 307/02 e $n^{\circ} 448 / 12$, é obrigatoriedade do município gerenciar os resíduos provenientes dos pequenos geradores. Diante desse contexto, Limeira possui 11 Ecopontos ativos para que pessoas físicas ou jurídicas possam destinar diariamente até $1 \mathrm{~m}^{3} \mathrm{de}$ RCC. As condições para operação dos Ecopontos encontram-se nas Leis Municipais n 4.561/10 e $n^{\circ}$ 5.300/14. A elaboração do "Programa para os Pequenos Geradores de Resíduos da Construção Civil" contou com a participação dos profissionais do Centro de Promoção Social Municipal de Limeira (Ceprosom), que são responsáveis pelo cadastro e treinamento dos colaboradores dos Ecopontos.

Uma das grandes dificuldades da operação dos Ecopontos é a deficiência da segregação dos RCC na fonte, pois frequentemente são entregues resíduos misturados nas caçambas disponíveis nos Ecopontos, que deveriam receber apenas RCC classe A. Para diminuir esse hábito, os colaboradores dos Ecopontos estão sendo treinados men- 
salmente, para que possam diferenciar os resíduos da construção civil de um resíduo industrial, por exemplo. Outro problema encontrado é o uso inadequado dos Ecopontos por grandes geradores, que fracionam o volume total gerado e realizam diversas viagens em um único dia. Nesse sentido, será necessário um controle mais efetivo das pessoas que utilizam os Ecopontos, mediante o cadastramento dos transportadores autônomos de pequenos volumes de RCC.

As dificuldades relacionadas ao gerenciamento dos Ecopontos é retratada por outros autores; nos Ecopontos do município de São Carlos-SP, foram encontrados pequenos descartes clandestinos de RCC e volumosos pulverizados nas proximidades dos Ecopontos (CÓRDOBA et al., 2011) e nos Ecopontos do município de Uberaba-MG, Silva e Fernandes (2012) destacaram que um dos principais problemas é o recebimento de resíduos eletrônicos, os quais contêm metais pesados entre outros contaminantes.

Foi previsto o estudo de novas áreas para a implantação de outros Ecopontos, a adequação dos Ecopontos atuais à NBR 15.112 (ABNT, 2004) e, a melhoria da comunicação visual desses locais.

\subsubsection{Grandes geradores de RCC}

Como estabelecido nas Resoluções Conama $n^{\circ} 307 / 02$ e no 448/12, os grandes volumes de RCC são de responsabilidade do próprio gerador, e somente poderão ser dispostos em locais licenciados pelo órgão ambiental responsável.

Nos anexos do PMGRCC foi disponibilizado um modelo para elaboração dos Planos de Gerenciamento de RCC (PGRCC). No entanto, para não burocratizar o sistema, apenas para áreas construídas acima de $500 \mathrm{~m}^{2}$ o gerador deverá elaborar o PGRCC, o qual deverá ser apresentado na solicitação de Alvará de Construção e ou Alvará de Demolição.
Entretanto, para construções e demolições com até $500 \mathrm{~m}^{2}$, o gerador deverá apresentar uma declaração atestando o conhecimento das suas responsabilidades quanto à geração e destinação ambientalmente correta dos RCC. O responsável técnico pela obra também deverá apresentar uma declaração confirmando a responsabilidade em controlar e orientar o proprietário quanto à correta destinação dos resíduos gerados e a exigência do Controle de Transporte de Resíduos (CTR). Apesar de essa iniciativa representar um avanço em relação ao sistema de gerenciamento atual, sabe-se que a maioria das obras realizadas no município possui áreas inferiores a $500 \mathrm{~m}^{2}$; desse modo, a exigência da elaboração dos PGRCC abrangerá uma pequena parcela das obras.

Em resumo, para qualquer empreendimento gerador de RCC, a emissão do Habite-se ou Auto de Conclusão da Obra e a emissão da Certidão de Demolição deve estar condicionada à apresentação do CTR. Esse documento é emitido pelo transportador de resíduos, que deverá fornecer informações sobre o gerador, a origem, a quantidade, a tipologia dos resíduos e a destinação final. O plano disponibilizou um modelo de CTR, elaborado conforme as especificações da NBR 15.112 (ABNT, 2004).

\subsubsection{Gerenciamento de RCC em obras públicas}

Antes da elaboração do Plano não havia uma regulamentação municipal a respeito do gerenciamento dos RCC provenientes de obras públicas, as quais são realizadas principalmente por empresas contratadas. Desse modo, a partir do PMGRCC, todos os Termos de Referência, Memoriais Descritivos, Especificações Técnicas, Editais e outros documentos que subsidiem a contratação de obras públicas deverão incluir a exigência de implantação dos Planos de Gerenciamento de RCC.

Ficou definido que, para a assinatura do contrato, a Prefeitura Municipal de Limeira deverá exigir uma comprovação da regularidade dos agentes respon- 
sáveis pelas atividades de transporte, triagem e destinação final de RCC. As comprovações consistem na elaboração e execução do PGRCC e manutenção de registros e dos Controles de Transporte de Resíduos.

No futuro, além da elaboração dos PGRCC, as obras públicas (a princípio as de pavimentação) deverão incorporar a utilização de agregados reciclados. Essa etapa será fundamental para incentivar a instalação e operação de uma usina de reciclagem, pública ou privada, no município. Segundo Miranda (2005), devido à resistência em relação ao uso dos agregados reciclados por parte das construtoras, caso o Poder Público participe dessa cadeia, a partir do consumo ou apoio ao consumo, a questão da destinação de resíduos e da comercialização dos agregados reciclados pode ser solucionada.

\subsubsection{Mecanismos de controle e fiscalização}

Os principais agentes envolvidos no sistema de gerenciamento de RCC são as empresas que realizam as etapas de armazenamento temporário, coleta e transporte dos RCC até a reutilização, reciclagem ou disposição final no aterro de inertes. O município possui leis que disciplinam o uso das caçambas; no entanto, devido à ausência de fiscalização, as mesmas não são obedecidas.

Em algumas reuniões estiveram presentes empresários do setor de locação e transporte das caçambas, os quais foram instruídos a esclarecer que a responsabilidade do armazenamento dos RCC é do gerador, como estabelece a Resolução Conama n 307/02: "os geradores de resíduos da construção civil devem ser responsáveis pelos resíduos das atividades de construção, reforma, reparos e demolições de estruturas e estradas, bem como por aqueles resultantes da remoção de vegetação e escavação de solos" (BRASIL, 2002, p. 1). Para isso, sugere-se a elaboração de um contrato prévio entre o gerador (pessoa física ou jurídica) e a empresa de locação e transporte de caçamba.
Desse modo, caso haja contaminação dos resíduos da construção civil com outros tipos de resíduos, como os resíduos sólidos urbanos ou resíduos perigosos, o munícipe deverá pagar pela disposição adequada do resíduo, que poderá ser em aterro sanitário, aterro de resíduos perigosos ou outra forma de destinação final, de acordo com as características do contaminante.

Existe um relato comum nas cidades brasileiras de que, muitas vezes, quem contrata o serviço de caçamba não costuma dispor outros tipos de resíduos misturados ao RCC, mas que munícipes vizinhos se aproveitam dos dispositivos para descartar resíduos impróprios. Nesse sentido, a utilização de tampas nas caçambas pode auxiliar no controle do armazenamento de resíduos no canteiro de obras, ou quando possível, manter a caçamba no interior da obra, impossibilitando que outras pessoas externas tenham acesso ao compartimento.

Em relação ao transporte, as regras estabelecidas no Código de Trânsito Brasileiro (Lei nº. 9503/97) devem ser seguidas, e o Plano também determina que as empresas físicas ou jurídicas que transportam RCC deverão identificar os caminhões transportadores e as caçambas com nome da empresa e telefone, pois caso haja alguma irregularidade isso facilitará o serviço de fiscalização.

Como não há previsão para a implantação do SIGOR, é necessário que o Município inicie a implantação de um sistema de gerenciamento de RCC contendo os mecanismos necessários para controle e fiscalização das empresas ou pessoas físicas que prestem serviços de coleta, transporte, beneficiamento e disposição final de RCC ou resíduos volumosos.

A fiscalização voltada ao descarte irregular de RCC, com ênfase na limpeza urbana do Município, deve contemplar as atividades informativas de mobilização social por meio de legislação específica que possibilite a atuação, nos limites da lei, no sentido de punir os responsáveis pelo descumprimento da mesma. 


\subsubsection{Educação ambiental e Mobilização social}

O principal objetivo do "Programa de Educação Ambiental" é sensibilizar a população residente no município de Limeira sobre a responsabilidade individual no gerenciamento dos RCC, enfatizando a importância da não geração, redução, reutilização e reciclagem dos resíduos sólidos, e da disposição final ambientalmente adequada dos rejeitos.

Orientações sobre o uso correto dos Ecopontos e das caçambas estacionárias necessitam de ampla divulgação, a fim de evitar a mistura de RCC com potencial de reutilização e reciclagem com resíduos domiciliares, animais mortos, resíduos de serviço de saúde, resíduos industriais, entre outros. Para a melhoria desse cenário, é fundamental informar sobre os impactos ambientais e econômicos e as penalidades do descarte irregular, e sobre os locais disponíveis para o descarte adequado.

As atividades contempladas pelo programa incluem a capacitação dos gestores públicos atuantes do processo de gerenciamento dos resíduos sólidos, e a sensibilização dos agentes privados atuantes no setor de construção civil e da sociedade, por meio de palestras, cursos, materiais informativos, entre outros.

Uma política de comunicação constante e de fácil compreensão, que atenda toda a população, é uma ferramenta útil para minimizar a falta de informação sobre os resíduos da construção civil e o desinteresse em manter a limpeza urbana em condições adequadas. Os serviços e programas existentes no Município, como o Programa "Só Cacareco" que coleta gratuitamente móveis inservíveis nas residências, devem ser amplamente divulgados, a fim de incentivar o envolvimento da comunidade sobre as questões referentes aos resíduos e a necessidade de mudança de comportamento.

\subsection{Avanços e perspectivas futuras}

No decorrer da revisão dos programas e ações, o grupo de trabalho promoveu o curso gratuito "Gestão Integrada de Resíduos da Construção Civil", com o objetivo de disseminar informações sobre a gestão dos resíduos no canteiro de obras e a aplicação dos agregados reciclados nas construções. Além dos conhecimentos teóricos ministrados por palestrantes da Abrecon no auditório da Faculdade de Tecnologia da Unicamp, os participantes visitaram uma Usina de Reciclagem de RCC com a finalidade de demonstrar a viabilidade técnica e econômica do uso dos agregados reciclados. O público-alvo foi composto de colaboradores da Prefeitura de Limeira, empresários e profissionais do setor da construção civil e manejo nos RCC no Município, estudantes e demais interessados sobre o tema, sendo que ao todo participaram 104 profissionais e 57 estudantes de nível universitário.

Após 15 reuniões, a versão preliminar do PMGRCC foi concluída, e permaneceu disponível no site da Prefeitura de Limeira, em conjunto com um formulário para que os interessados enviassem as críticas e sugestões sobre o Plano. Após nove dias, houve a audiência pública, na qual o Plano foi apresentado. Estiveram presentes por volta de cem pessoas, as quais contribuíram com seus questionamentos e sugestões, para a elaboração da versão final do Plano, publicada e aprovada por meio do Decreto Municipal $n^{\circ} 304$, de $1^{\circ}$ de outubro de 2015.

Durante as etapas de elaboração do PMGRCC de Limeira, duas das metas imediatas inicialmente propostas foram cumpridas: (i) solicitação da adesão do Município ao SIGOR; para isso, a Prefeitura Municipal de Limeira enviou um ofício para Secretaria Estadual de Meio Ambiente solicitando a inclusão do Município no Sistema, o pedido foi aceito e, dessa maneira, o município de Limeira encontra-se na lista de espera para o cadastro dos usuários da Prefeitura e dos demais setores; (ii) determinação de um preço público diferenciado de $\mathrm{R} \$ 89,87 / \mathrm{m}^{3}$ para o recebimento de caçambas com resíduos da 
construção civil misturados com outras classes de resíduos (como os domiciliares e industriais não perigosos) no aterro municipal, visto que as mesmas não serão enviadas para o aterro de inertes, mas para o aterro sanitário. Esse novo valor foi publicado em outubro de 2015 no Jornal Oficial do Município, e tem como principal objetivo incentivar a melhoria da triagem no canteiro de obras.

Para que a execução do Plano tenha uma continuidade, será imprescindível a estruturação e formalização de um núcleo gestor para implantação e monitoramento do Plano, com a participação de funcionários efetivos da Prefeitura, bem como a criação de um Programa de Educação Ambiental voltado à população com inclusão dos pequenos $\mathrm{e}$ grandes geradores de resíduos da construção civil, em conjunto com ações de fiscalização.
Em relação aos recursos econômicos para atender as medidas previstas no PMGRCC, faz-se necessária uma previsão da dotação orçamentária no Plano Plurianual Municipal de Limeira. Por fim, o conteúdo do Plano deve ser revisado e aprimorado periodicamente, a fim de garantir a sua atualização diante das alternativas e tecnologias atuais para a gestão e gerenciamento dos RCC.

Por fim, cabe ressaltar que o gerenciamento integrado dos RCC deve considerar os PGRCC elaborados pelos grandes geradores, e tanto esses planos como o PMGRCC devem lançar mão das tecnologias atuais do setor, de forma a atender às diretrizes das Resoluções Conama n 307/02 e n 448/12, em conjunto com a hierarquia dos resíduos sólidos preconizada pela Política Nacional de Resíduos Sólidos, conforme ilustra o modelo apresentado na Figura 4.

Figura 4 - Modelo de Gerenciamento integrado de resíduos da construção civil.

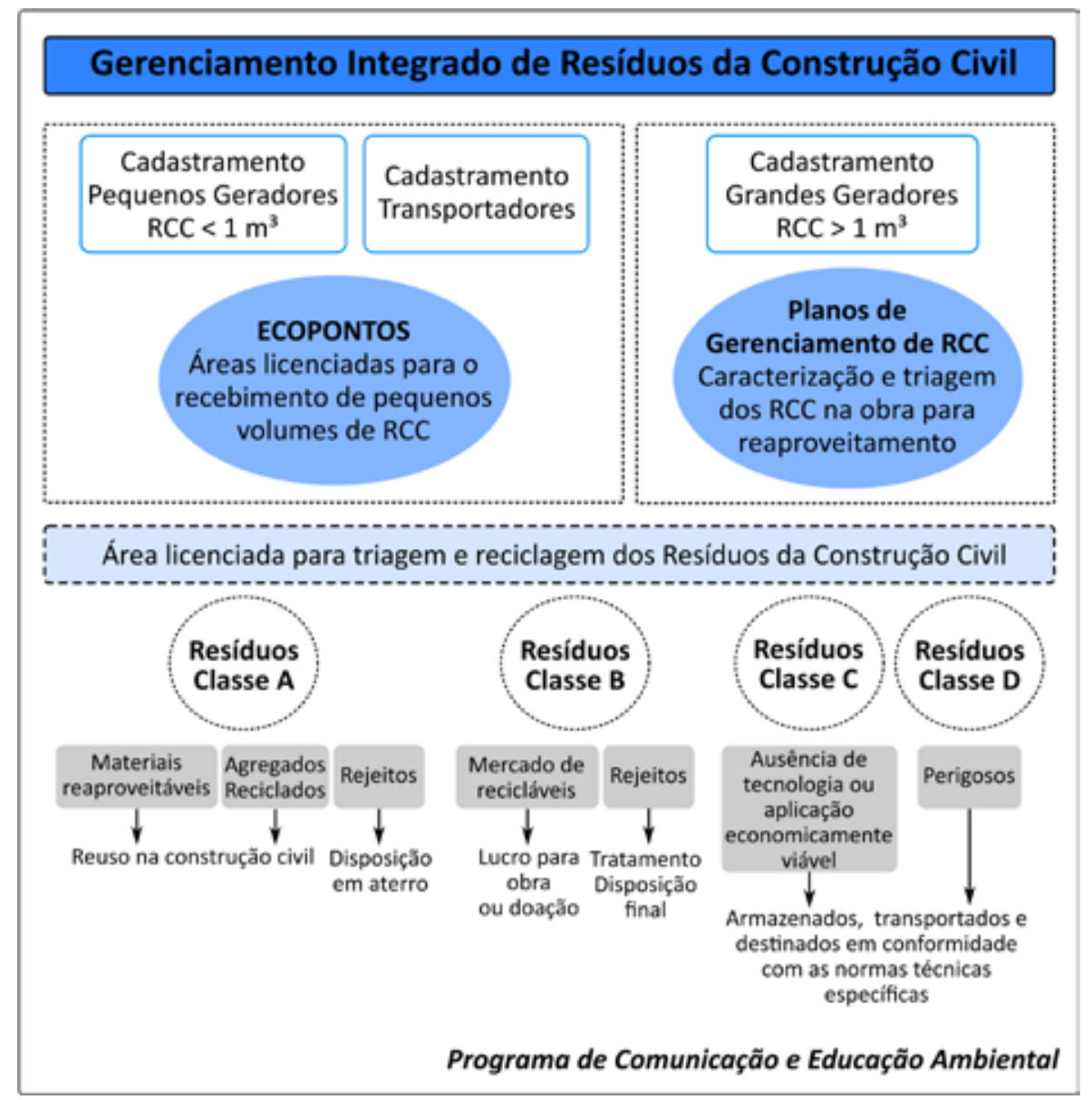




\section{CONCLUSÃO}

Neste artigo foram descritas todas as etapas envolvidas na concepção do Plano Municipal de Gestão dos Resíduos da Construção Civil de Limeira-SP, que ocorreu de forma participativa, unindo o setor público, privado e a sociedade. A partir de um grupo de trabalho com amplo conhecimento do manejo dos RCC no Município, crítico e participativo, foi possível elaborar um diagnóstico que reflete a realidade, o que resultou em um plano de gerenciamento com metas, programas e ações coerentes e passíveis de serem alcançadas dentro do cronograma proposto.

Uma das evidências da participação pública foi a presença de um número considerável de pessoas nos eventos realizados e na audiência pública. Com isso, foi possível compreender os principais desafios do gerenciamento dos RCC, como a falta de informação sobre as responsabilidades de cada agente envolvido.

A participação da Universidade no processo de elaboração do Plano foi uma via de mão dupla. A universidade contribuiu com a visão crítica pautada em resultados de projetos de pesquisa recentes sobre o diagnóstico do gerenciamento de RCC no Município, e com o conhecimento técnico-científico especializado sobre práticas de gestão e tecnologias atuais de gerenciamento de RCC. Por outro lado, a participação na elaboração do Plano proporcionou aos representantes da Universidade a grata satisfação de ver os resultados de pesquisas serem aplicados na resolução dos problemas no âmbito do município em que está inserida, além de proporcionar o conhecimento mais profundo das leis e outros instrumentos que serviram como arcabouço para a finalização do plano.

Outros aspectos, como a regularidade das reuniões e a comunicação com as empresas que atuam na coleta e transporte dos RCC até o destino final, foram essenciais para o cumprimento das atividades previstas no cronograma.
No entanto, não se pode deixar de ressaltar um dos grandes desafios na sustentabilidade de planos de gerenciamento no Brasil, que é a descontinuidade das ações de uma gestão municipal pela gestão sucessora. Nesse sentido, apesar de haver um decreto municipal que aprova o PMGRCC de Limeira, é de vital importância à estruturação e formalização de um núcleo gestor, com agentes dos setores público e privado em conjunto com agentes da sociedade e outras instituição interessadas, garantindo a execução, revisão e continuidade do plano elaborado.

Nesse sentido, este artigo fornece subsídios à pesquisadores e gestores no âmbito público e privado, para a elaboração de planos de gerenciamento de RCC, ressaltando a importância de pontos críticos, que muitas vezes são negligenciados na gestão de resíduos, tais como: responsabilidades de pequenos e grandes geradores de RCC; gerenciamento de RCC em obras públicas; mecanismos de flexibilização e fiscalização; e, importância da educação ambiental e da mobilização social.

\section{AGRADECIMENTOS}

À Capes (Coordenação de Aperfeiçoamento de Pessoal de Nível Superior) pela bolsa de doutorado.

\section{REFERÊNCIAS}

ÂNGULO, S. C.; TEIXEIRA, C. E.; CASTRO, A. L.; NOGUEIRA, T. P. Resíduos de construção e demolição: avaliação de métodos de quantificação. Engenharia Sanitária e Ambiental, v. 16, n. 3, p. 299-306, 2011.

AZEVEDO, G. O. D.; KIPERSTOK, A.; MORAES, L. R. S. Resíduos da Construção Civil em Salvador: Os Caminhos para uma Gestão Sustentável. Engenharia Sanitária e Ambiental, v. 11, n. 1, p. 6572, 2006.

ABRELPE. Panorama dos resíduos sólidos no Brasil 2016. Associação Brasileira de Limpeza Pública e Resíduos Especiais. Disponível em: <http://www.Abrelpe.org.br>. Acesso em: 05 out. 2016.

ASSOCIAÇÃO BRASILEIRA DE NORMAS TÉCNICAS. NBR 15.112: resíduos da construção civil e resíduos volumosos - áreas de 
transbordo e triagem - diretrizes para projeto, implantação e operação. Rio de Janeiro, 2004.

BRASIL. Ministério do Meio Ambiente. Conselho Nacional do Meio Ambiente (Conama). Resolução n 307, de 05 de Julho de 2002. Dispõe sobre a gestão de resíduos da construção civil. Brasília: Ministério do Meio Ambiente, 2002.

BRASIL. Lei nº 9.503, de 23 de setembro de 1997. Institui o Código de Trânsito Brasileiro. Brasília, DF, 1997.

BRASIL. Lei n 11.445, de 5 de janeiro de 2007. Estabelece diretrizes nacionais para o saneamento básico. Brasília, DF, 2007.

BRASIL. Lei n $^{\circ}$ 12.305, de 2 de agosto de 2010. Institui a Política Nacional de Resíduos Sólidos; altera a Lei n 9.605, de 12 de fevereiro de 1998; e dá outras providências. Brasília, DF.

BRASIL. Ministério do Meio Ambiente. Guia para elaboração dos Planos de Gestão de Resíduos Sólidos. Brasília: Ministério do Meio Ambiente, 2011.

BRASIL. Ministério do Meio Ambiente. Conselho Nacional do Meio Ambiente (Conama). Resolução $\mathbf{n}^{\circ}$ 448, de 18 de Janeiro de 2012. Altera os arts. $2^{\circ}, 4^{\circ}, 5^{\circ}, 6^{\circ}, 8^{\circ}, 9^{\circ}, 10$ e 11 da Resolução $n^{\circ} 307$, de 5 de julho de 2002, do Conselho Nacional do Meio Ambiente. Brasília: Ministério do Meio Ambiente, 2012a.

BRASIL. Ministério do Meio Ambiente. Planos de gestão de resíduos sólidos: manual de orientação. Brasília: Ministério do Meio Ambiente, 2012b.

CARBONE, A. S.; COUTINHO, S. M. V.; TOMERIUS, S.; PHILIPPI JUNIOR, A. Gestão de Áreas Verdes no Município de São Paulo: Ganhos e Limites. Ambiente \& Sociedade, v. XVIII, n. 4, p. 201-220, 2015.

CARMO, D. S.; MAIA, N. S.; CÉSAR, C. G. Avaliação da tipologia dos resíduos de construção civil entregues nas usinas de beneficiamento de Belo Horizonte. Engenharia Sanitária e Ambiental, v. 17, n. 2, p. 187-192, 2012.

CETESB. Inventário Estadual de Resíduos Sólidos Domiciliares 2014. Companhia Ambiental do Estado de São Paulo. São Paulo: CETESB, 2015.

CETESB. Sistema Estadual de Gerenciamento Online de Resíduos Sólidos - SIGOR. Companhia Ambiental do Estado de São Paulo. 2015.

CERVO, A. L.; BERVIAN, P. A.; DA SILVA, R. Metodologia científica. 6. ed. São Paulo: Pearson Prentice Hall, 2007.

COSTA, N.; COSTA JR, N.; LUNA, M.; SELIG, P. Planejamento de Programas de Reciclagem de Resíduos de Construção e Demolição no Brasil: uma Análise Multivariada. Engenharia Sanitária e Ambiental, v. 12, n. 4, p. 446-456, 2007.

DALFRÉ, R. R.; MESQUUITA, R.; BOZI, P. C. Diagnóstico da situação dos ecopontos no município de Limeira-SP. In: EXPOSIÇÃO DE EXPERIÊNCIAS MUNICIPAIS EM SANEAMENTO, 18., 2014, Uberlândia. Anais... Brasília: ASSEMAE, 2014. 1 CD-ROM.
FERNANDES, M. da P. M.; SILVA FILHO, L. C. P. da. Um modelo orientativo para a gestão municipal dos RCCs. Ambiente Construído, Porto Alegre, v. 17, n. 2, p. 21-38, abr./jun. 2017.

GALARZA, L.H.W.; GÓMEZ, S.T.R.; GARCEZ, E.O.; CORREA, É.C.; PORRAS, Á.C.; FORERO, I.H. Modelo dinâmico de sistemas para o gerenciamento de resíduos da construção civil na cidade de Porto Alegre: estudo de caso. Engenharia Sanitária e Ambiental, v. 20, n. 3, p. 463-474, 2015.

GOMES, M. H. S. C.; OLIVEIRA, E. C.; BRESCIANI, L. P.; PEREIRA, R. S. Política Nacional de Resíduos sólidos: perspectivas de cumprimento da Lei 12.305/2010 nos municípios brasileiros, municípios paulistas e municípios da região do ABC. Rev. Adm. UFSM, Santa Maria, v. 7, Edição Especial, p. 93-110, nov. 2014.

IBGE. Limeira: Infográficos - evolução populacional e pirâmide etária. Instituto Brasileiro de Geografia e Estatística. 2016.

JORNAL OFICIAL DO MUNICÍPIO DE LIMEIRA. Tabela de Preços Públicos. Edição 4618, de 11 de outubro de 2015.

LIMA, A. S.; CABRAL, A. E. B. Caracterização e classificação dos resíduos de construção civil da cidade de Fortaleza (CE). Engenharia Sanitária e Ambiental, v. 18, n. 2, p. 169-176, 2013.

LIMEIRA (Município). Lei $\mathbf{n}^{\circ} \mathbf{4 . 8 1 2 / 2 0 1 1}$, Regulamenta a coleta, triagem, reutilização, reciclagem, reservação ou destinação, disposição e o transporte de Resíduos de Construção Civil e Resíduos Volumosos no Município de Limeira. 2011.

LIMEIRA (Município). Plano Municipal de Saneamento de Limeira/SP. Volume 5 - Limpeza Urbana e Manejo de Resíduos Sólidos. Prefeitura Municipal de Limeira. Revisão 1. 2014.

LIMEIRA (Município). Decreto $\mathbf{n}^{\circ}$ 304, de $\mathbf{1}^{\circ}$ de outubro de 2015. Aprovação do Plano Municipal de Gestão de Resíduos da Construção Civil (PMGRCC) do Município de Limeira. Jornal Oficial do Município, Edição 4615, de 02 de outubro de 2015.

LOPES, L. Gestão e gerenciamento integrado dos resíduos sólidos urbanos. São Paulo, 2006. 113 f. Dissertação (Mestrado em Geografia Humana) - Faculdade de Filosofia, Letras e Ciências Humanas, Universidade de São Paulo, São Paulo, 2006.

MARCONI, M. A.; LAKATOS, E. M. Metodologia Científica. 6. ed. São Paulo: Atlas, 2011.

ORSI, R. A. Gestão participativa dos resíduos sólidos urbanos. Rio Claro, 2006. 137 f. Dissertação (Mestrado em Geografia) Universidade Estadual Paulista, Rio Claro, 2006.

OSMANI, M. Construction Waste. In: Waste - A Handbook for Management. Burlington, MA, USA: Academic Press, 2011. Chapter 15. p. $207-218$.

PINTO, T. P.; GONZÁLEZ, J. L. R. (Coord.) Manejo e gestão de resíduos da construção civil. 196 p.: il., v. 1, Brasília, DF: Caixa Econômica Federal, 2005. ISBN: 85-86836-04-4. 
ROSADO, L. P. Avaliação do Ciclo de Vida de Alternativas para o Gerenciamento Integrado de Resíduos da Construção Civil do Município de Limeira/SP, Brasil. Limeira, 2015. 386 f. Dissertação (Mestrado em Inovação e Tecnologia) - Faculdade de Tecnologia, Universidade Estadual de Campinas, Limeira, 2015.

SANTOS, M. N. Gerenciamento Integrado de Resíduos Sólidos: Estudo de Caso no Instituto Butantan. São Paulo, 2015. 145 f. Dissertação (Mestrado Profissional em Ambiente, Saúde e Sustentabilidade) - Faculdade de Saúde Pública, Universidade de São Paulo, São Paulo, 2015.

SÃO PAULO (Estado). Secretaria do Meio Ambiente. Plano de Resíduos Sólidos do Estado de São Paulo. Secretaria do Meio Ambiente do Estado de São Paulo, Coordenadoria de Planejamento Ambiental, Cetesb; Autores André Luiz Fernandes Simas [et al.];
Organizadores André Luiz Fernandes Simas, Zuleica Maria de Lisboa Perez. São Paulo: SMA, 2014.

SCREMIN, L. B.; CASTILHOS JUNIOR, A. B., ROCHA, J. C. Sistema de apoio ao gerenciamento de resíduos de construção e demolição para municípios de pequeno porte. Engenharia Sanitária e Ambiental, v. 19, n. 2, p.203-206, 2014.

TAKENAKA, E. M. M. Políticas públicas de gerenciamento integrado de resíduos sólidos urbanos no município de Presidente Prudente-SP. Presidente Prudente, 2008. 234 f. Tese (Doutorado em Geografia) - Universidade Estadual Paulista, Presidente Prudente, 2008.

TENÓRIO, F. G.; ROZENBERG, J. E. Gestão pública e cidadania: metodologias participativas em ação. Rio de Janeiro, v. 31, n. 4, p. 101-125, 1997. 